W. Ricart · J. López · J. Mozas · A. Pericot • M. A. Sancho • N. González •

M. Balsells $\cdot$ R. Luna $\cdot$ A. Cortázar $\cdot$ P. Navarro $\cdot$ O. Ramírez $\cdot$ B. Flández $\cdot$

L. F. Pallardo - A. Hernández · J. Ampudia - J. M. Fernández-Real · R. Corcoy •

Spanish Group for the Study of the Impact of Carpenter and Coustan GDM thresholds

\title{
Potential impact of American Diabetes Association (2000) criteria for diagnosis of gestational diabetes mellitus in Spain
}

Received: 21 July 2004 / Accepted: 28 January 2005 / Published online: 12 May 2005

(C) Springer-Verlag 2005

Abstract Aims/hypothesis: This study was carried out to
determine the impact of American Diabetes Association
(ADA) 2000 criteria for the diagnosis of gestational diabetes
mellitus (GDM) in the Spanish population. Methods: Preg-
nant women were assigned to one of four categories: neg-
ative screenees, false-positive screenees, ADA-only-GDM
(untreated) and GDM according to National Diabetes Data
Group (NDDG) criteria (treated). Fetal macrosomia and
Caesarean section were defined as primary outcomes, with

W. Ricart $(\bowtie) \cdot J$. M. Fernández-Real

Unit of Diabetes,

Endocrinology and Nutrition,

Hospital Universitari

de Girona Doctor Josep Trueta,

Avgda. de França s.n.,

17007 Girona, Spain

e-mail: uden.wricart@htrueta.scs.es

Tel.: +34-972-940225

Fax: +34-972-227443

J. López

Hospital Virgen de la Salud,

Toledo, Spain

J. Mozas

Hospital Universitario Virgen

de las Nieves,

Granada, Spain

A. Pericot

Hospital Clínic Universitari de Barcelona,

Barcelona, Spain

M. A. Sancho

Hospital Clínico Universitario

Lozano Blesa,

Zaragoza, Spain

N. González

Hospital Universitario de Canarias,

Tenerife, Spain

M. Balsells

Hospital Mutua de Terrassa,

Terrassa, Spain seven additional secondary outcomes. Results: Of 9,270 pregnant women screened for GDM, $819(8.8 \%)$ met NDDG criteria. If the threshold for defining GDM had been lowered to ADA criteria, an additional $2.8 \%$ of women would have been defined as having the condition (relative increase of $31.8 \%$ ). Maternal characteristics of women with ADA-onlyGDM were between those of false-positive screenees and women with NDDG-GDM. The risk of diabetes-associated complications was slightly elevated in the individuals who

R. Luna

Complejo Hospitalario Universitario Xeral-Cíes de Vigo,

Vigo, Spain

A. Cortázar

Hospital de Cruces,

Barakaldo, Spain

P. Navarro

Hospital General Universitario,

Alicante, Spain

O. Ramírez

Hospital Universitario

Materno-Infantil de Canarias,

Las Palmas de Gran Canaria, Spain

B. Flández

Hospital Universitario de Getafe,

Getafe, Spain

L. F. Pallardo

Hospital La Paz,

Madrid, Spain

A. Hernández

Hospital Universitario Dr Peset,

Valencia, Spain

J. Ampudia

Hospital Clínico de Valencia,

Valencia, Spain

R. Corcoy

Hospital de Sant Pau,

Barcelona, Spain 
would have been classified as abnormal only after the adoption of ADA criteria. In addition, the ADA-only-GDM contribution to morbidity was lower than that of other variables, especially BMI. Conclusions/interpretation: Use of the ADA criteria to identify GDM would result in a $31.8 \%$ increase in prevalence compared with NDDG criteria. However, as the contribution of these additionally diagnosed cases to adverse GDM outcomes is not substantial, a change in diagnostic criteria is not warranted in our setting.

Keywords Body mass index - Caesarean section - Fetal macrosomia $\cdot$ Gestational diabetes

\begin{abstract}
Abbreviations ADA: American Diabetes Association GCT: glucose challenge test - GDM: gestational diabetes mellitus · LGA: large for gestational age - MCM: major congenital malformation - NDDG: National Diabetes Data Group · OR: odds ratio - PIH: pregnancy-induced hypertension $\cdot$ SGA: small for gestational age
\end{abstract}

\section{Introduction}

Gestational diabetes mellitus (GDM) is defined as carbohydrate intolerance with onset or first recognition during pregnancy [1]. It increases the risk of adverse complications for both mother and child [1], a risk that can be reduced with appropriate diagnosis and treatment $[2,3]$. In 1998, the Toronto Tri-Hospital Gestational Diabetes Project [4] reported an increased rate of pre-eclampsia, Caesarean section and macrosomia in women with untreated borderline GDM who fulfilled the more stringent Carpenter and Coustan criteria [5], but not the National Diabetes Data Group (NDDG) criteria [6]. In 2000, the American Diabetes Association (ADA) shifted from NDDG to Carpenter and Coustan thresholds [7], and with these criteria, GDM prevalence increased by an average of $50 \%$ in the multiethnic American population [8-10]. However, the predictive ability of these criteria in terms of pregnancy outcome has not been fully investigated in non-American populations. As the prevalence of macrosomia and pregnancyinduced hypertension $(\mathrm{PIH}) /$ pre-eclampsia is lower in Spanish women than in their Canadian counterparts [4, $11,12]$, even if Spanish women with GDM according to ADA but not NDDG criteria had relative risks similar to those of Canadian women, their absolute risks would be lower. Thus, before deciding whether or not to adopt new criteria in the Spanish population, we evaluated the potential impact of a change from NDDG to ADA criteria on GDM prevalence, and the morbidity in women diagnosed as having GDM according to ADA but not NDDG criteria.

\section{Subjects, materials and methods}

This prospective study was conducted in 16 general hospitals of the Spanish National Health Service in 2002. All women with singleton pregnancies and without a former diagnosis of diabetes mellitus were considered for GDM screening at 24-28 weeks of gestation with a 50-g glucose challenge test (GCT). Women who had a venous plasma glucose $>7.8 \mathrm{mmol} / 1$ were scheduled for a diagnostic, 100 -g, 3-h OGTT. Both NDDG (fasting: $5.8 \mathrm{mmol} / \mathrm{l}, 1 \mathrm{~h}: 10.6$ mmol/l, $2 \mathrm{~h}: 9.2 \mathrm{mmol} / \mathrm{l}, 3 \mathrm{~h}: 8.1 \mathrm{mmol} / \mathrm{l}$ ) [6] and ADA criteria (fasting: $5.3 \mathrm{mmol} / 1,1 \mathrm{~h}: 10 \mathrm{mmol} / 1,2 \mathrm{~h} 8.6 \mathrm{mmol} /$ 1, $3 \mathrm{~h}: 7.8 \mathrm{mmol} / \mathrm{l}$ ) were considered [5]. With both criteria, GDM was defined when more than two plasma glucose measurements were equal to or higher than the cut-off points. The term 'ADA only gestational diabetes' (ADAonly-GDM) was used to refer to pregnant women who would be diagnosed as having GDM by ADA but not by NDDG criteria [13].

Following the method of Magee et al. [9], four glucose tolerance groups were defined: women with GDM according to NDDG criteria receiving usual care (NDDGGDM group) and three untreated groups, representing a gradient of carbohydrate tolerance. Negative screenees had a glucose value below $7.8 \mathrm{mmol} / \mathrm{l}$ on GCT. False-positive screenees had a positive GCT but a normal OGTT by ADA criteria and did not receive specific treatment [5]. Women with NDDG-GDM were managed with diet and self-monitoring of blood glucose. Insulin was added when required according to the local protocol (ADA recommendations [7], or lower thresholds in some centres [14]). All women received routine prenatal care.

Data collected included: maternal age, prepregnancy BMI, metabolic therapy during pregnancy, chronic hypertension (prior to pregnancy or diagnosed before 20 weeks of gestational age), PIH (when diagnosed after 20 weeks of gestational age, irrespective of proteinuria so that it also included pre-eclampsia), delivery (gestational age, spontaneous/induced, vaginal/Caesarean section), reason for Caesarean section (elective/dystocia/fetal distress/others) and newborn characteristics (birthweight, sex, Apgar score, perinatal mortality). Newborns were defined as large for gestational age (LGA) when sex-specific birthweight for gestational age was above the 90th percentile of Spanish fetal growth curves [15]. Gestational age was defined as completed weeks, based on last menstrual period or on the earliest ultrasound assessment if discordant. Before hospital discharge, newborns were examined for major congenital malformations (MCMs), defined as those causing significant functional or cosmetic impairment, requiring surgery, or being life-limiting.

Macrosomia (defined as a birthweight at or above $4 \mathrm{~kg}$ ) and Caesarean section were defined as primary outcomes. Sample size $(n=9,741)$ was calculated to detect a two-fold increase in the rate of macrosomia and a $40 \%$ increase in the rate of Caesarean section in the subgroup of women fulfilling ADA-only-GDM criteria, assuming baseline rates of 4 and $12 \%$ respectively $(\alpha=0.05$ and $\beta=0.80)$. These figures were chosen because they are the relative risks observed in the Toronto Tri-Hospital Study [4]. Secondary outcomes were the rate of LGA newborns, preterm birth, $\mathrm{PIH}$, Apgar score $<7$ at 1 and $5 \mathrm{~min}, \mathrm{MCM}$ and perinatal mortality. The projected sample size was calculated to be 
insufficient to detect a $70 \%$ increase in the risk of PIH in the ADA-only-GDM group (observed for pre-eclampsia in the Toronto Tri-Hospital Study) assuming a baseline rate of $2 \%$.

Glucose tolerance groups were compared using a chi square test for qualitative variables and ANOVA for quantitative variables. When overall analyses were significant, all possible intergroup comparisons were made. Multiple logistic regression analysis with a backward method was used to calculate adjusted odds ratios (ORs) for developing complications and $95 \%$ CIs. All potentially predictive variables were fed into the model; BMI was modelled as a categorical variable and maternal age as a continuous variable. Significance was set at a two-tailed $p<0.05$.

\section{Results}

The study recruited 9,513 consecutive women aged 14-45 years. Ethnicity was $91.8 \%$ Caucasian, $0.7 \%$ African, $0.7 \%$
Asian, 2.5\% Arab, 2.7\% Caribbean and 1.6\% other. We excluded 206 women (2.2\%) who did not undergo screening and 37 with non-available results. The final study group was therefore made up of the remaining 9,270 (97.4\%) pregnant women.

Table 1 shows maternal characteristics and plasma glucose levels in the screening and diagnostic tests. A total of 819 (8.8\%) women met NDDG criteria and $263(2.8 \%)$ also met ADA-only-GDM criteria. Applying ADA thresholds to this population, GDM prevalence increased by $31.8 \%$. Glucose tolerance was not related to non-Caucasian ethnicity. Prevalence of chronic hypertension and mean age, weight and BMI were higher in women with worse glucose tolerance, whereas mean height was lower in these women (overall $p<0.001$ ). As expected, the rates of fetal macrosomia and Caesarean section were higher in women with lower glucose tolerance. The rate of fetal macrosomia differed between negative screenees and the groups with worse glucose tolerance (overall $p<0.001$ ), but the differ-

Table 1 Maternal characteristics and clinical outcomes according to the glucose tolerance status

\begin{tabular}{|c|c|c|c|c|c|}
\hline & $\begin{array}{l}\text { Negative } \\
\text { screenees }\end{array}$ & $\begin{array}{l}\text { False-positive } \\
\text { screenees }\end{array}$ & $\begin{array}{l}\text { ADA-only-GDM } \\
\text { (untreated) }\end{array}$ & $\begin{array}{l}\text { NDDG-GDM } \\
\text { (treated) }\end{array}$ & Overall $p$ \\
\hline No. $(\%)$ & $6,350(68.5)$ & $1,838(19.8)$ & $263(2.8)$ & $819(8.8)$ & - \\
\hline Age (years) & $28.8 \pm 5.3$ & $30.5 \pm 4.9 *$ & $31.7 \pm 4.6^{*}, * *$ & $31.9 \pm 4.7 * * *$ & $<0.0001$ \\
\hline Weight (kg) & $61.8 \pm 10.9$ & $63.9 \pm 12.3 *$ & $65.5 \pm 12.7 * * *$ & $66.5 \pm 14.3^{*}, * *$ & $<0.0001$ \\
\hline Chronic hypertension (\%) & 0.6 & 0.7 & $1.9^{*}$ & $2.3 * * *$ & $<0.0001$ \\
\hline \multicolumn{6}{|l|}{ 50-g, 1-h OGTT } \\
\hline Glucose (mmol/l) & $5.7 \pm 1.4$ & $8.7 \pm 0.8^{*}$ & $8.9 \pm 1.2 *$ & $9.9 \pm 1.7 * * *, * * *$ & $<0.0001$ \\
\hline \multicolumn{6}{|l|}{ 100-g, 3-h OGTT } \\
\hline Fasting glucose & - & $4.6 \pm 0.6$ & $4.8 \pm 0.5^{*}$ & $5.0 \pm 0.9 * *, * * *$ & $<0.0001$ \\
\hline \multicolumn{6}{|l|}{ Primary outcomes } \\
\hline Macrosomia (\%) & 4.6 & $7.1^{*}$ & $8 *$ & $7.4^{*}$ & $<0.0001$ \\
\hline Caesarean section $(\%)$ & 19.2 & 21.4 & 22.5 & $24.8^{*}$ & 0.02 \\
\hline \multicolumn{6}{|l|}{ Secondary outcomes } \\
\hline $\mathrm{PIH}(\%)$ & 1.7 & 2.3 & $3.8^{*}$ & $4.2 *, * *$ & $<0.0001$ \\
\hline Gestational age (weeks) ${ }^{a}$ & $39.5 \pm 1.8$ & $39.5 \pm 1.7$ & $39.6 \pm 1.4$ & $39.2 \pm 1.9$ & $<0.0001$ \\
\hline Preterm birth $(\%)$ & 5.3 & 5.0 & $2.7 *$ & $7 * * *, * * *$ & 0.019 \\
\hline LGA $(\%)$ & 13.3 & $16.5^{*}$ & $20.5^{*}$ & $16.5^{*}$ & $<0.0001$ \\
\hline SGA $(\%)^{\mathrm{a}}$ & 7.0 & 5.7 & 6.5 & 7.2 & NS \\
\hline \multicolumn{6}{|l|}{ Apgar score } \\
\hline
\end{tabular}

Data are means \pm SD or percentages

$A D A$-only-GDM American Diabetes Association-only gestational diabetes mellitus, $N D D G$ - $G D M$ NDDG gestational diabetes mellitus, $L G A$ large for gestational age, $S G A$ small for gestational age, $P I H$ pregnancy-induced hypertension

${ }^{*} p<0.05$ or lower vs negative screenees; ${ }^{* *} p<0.05$ or lower vs false-positive screenees; $* * * p<0.05$ or lower vs ADA-only GDM

${ }^{a}$ Related variable, not considered as an outcome variable in the study design 
ences among the latter were not significant. Women with GDM according to NDDG criteria had a higher rate of Caesarean section than negative screenees ( 24.8 vs $19.2 \%$, $p=0.002$ ), but this was not the case for women with ADAonly-GDM ( 22.5 vs $19.2 \%$, NS). No differences in the reason for Caesarean section were seen between groups (data not shown). As to secondary outcomes, only the rates of PIH and LGA were higher in women with lower glucose tolerance (see Table 1 for details). In relation to negative screenees, preterm birth was less frequent in ADA-onlyGDM and more frequent in NDDG-GDM. There were no differences among glucose tolerance groups in low Apgar score at 1 and $5 \mathrm{~min}$, perinatal mortality, or MCM. Nor were differences observed among groups regarding the rate of small-for-gestational-age (SGA) newborns, a variable which was not included as an outcome, but is nevertheless related to glucose tolerance and hyperglycaemia.

Age and BMI were categorised in quartiles. As expected, GDM prevalence increased with age and BMI quartiles $(p<0.0001$ for trend in both). Each woman received a score for age and BMI corresponding to the quartile of the variable, and a combined score was constructed with the sum of the former. The lowest possible combined score was 2 , corresponding to women in the 1st quartile of age and BMI, whereas the highest possible combined score was 8 , corresponding to women in the 4th quartile for both age and

Table 2 Multivariate analysis for prediction of primary (macrosomia, Caesarean section) and secondary (PIH, LGA, preterm birth, Apgar $\left.1^{\prime}<7\right)$ outcomes

\begin{tabular}{|c|c|c|c|c|c|c|c|c|c|}
\hline \multirow[t]{2}{*}{ Predictive variables } & \multicolumn{3}{|c|}{ Macrosomia } & \multicolumn{3}{|l|}{$\mathrm{PIH}$} & \multicolumn{3}{|l|}{ LGA } \\
\hline & OR & $95 \% \mathrm{CI}$ & $p$ & OR & $95 \% \mathrm{CI}$ & $p$ & OR & $95 \% \mathrm{CI}$ & $p$ \\
\hline Glucose tolerance & & & 0.029 & & & 0.004 & & & NS \\
\hline Negative screenees & 1 & & & 1 & & & 1 & & \\
\hline False+screenees & 1.33 & $1.04-1.72$ & 0.026 & 1.25 & $0.83-1.90$ & NS & 1.15 & $0.97-1.35$ & NS \\
\hline ADA-only-GDM & 1.45 & $0.83-2.52$ & NS & 2.34 & $1.15-4.77$ & 0.019 & 1.44 & $1.02-2.03$ & 0.036 \\
\hline NDDG-GDM & 1.47 & $1.06-2.06$ & 0.022 & 2.03 & $1.30-3.16$ & 0.002 & 1.10 & $0.87-1.35$ & NS \\
\hline Maternal BMI & & & $<0.0001$ & & & $<0.0001$ & & & $<0.0001$ \\
\hline $\mathrm{Q} 1:<21.5 \mathrm{~kg} / \mathrm{m}^{2}$ & 1 & & & 1 & & & 1 & & \\
\hline Q2: $21.5-23.6 \mathrm{~kg} / \mathrm{m}^{2}$ & 1.51 & $1.08-2.10$ & 0.016 & 2.69 & $1.45-5.01$ & 0.020 & 1.24 & $1.02-1.51$ & 0.030 \\
\hline Q3: $23.7-26.1 \mathrm{~kg} / \mathrm{m}^{2}$ & 1.66 & $1.20-2.30$ & 0.002 & 2.21 & $1.17-4.19$ & 0.014 & 1.44 & $1.19-1.74$ & $<0.0001$ \\
\hline $\mathrm{Q} 4:>26.1 \mathrm{~kg} / \mathrm{m}^{2}$ & 2.52 & $1.85-3.43$ & $<0.0001$ & 5.77 & $3.24-10.3$ & $<0.0001$ & 2.08 & $1.73-2.50$ & $<0.0001$ \\
\hline Fetal sex (male) & 2.58 & $2.07-3.22$ & $<0.0001$ & 1.27 & $0.93-1.75$ & NS & 1.16 & $1.02-1.32$ & 0.02 \\
\hline Gestational age & 1.62 & $1.49-1.75$ & $<0.0001$ & 0.82 & $0.77-0.87$ & $<0.0001$ & 0.89 & $0.87-0.92$ & $<0.0001$ \\
\hline Maternal age & 1.00 & $0.99-1.03$ & NS & 0.98 & $0.95-1.01$ & NS & 1.01 & $0.99-1.02$ & NS \\
\hline Macrosomia (yes) & - & - & - & 0.32 & $0.10-1.02$ & 0.053 & - & - & - \\
\hline PIH (yes) & 0.32 & $0.10-1.02$ & NS & - & - & - & 0.43 & $0.25-0.74$ & 0.002 \\
\hline \multirow[t]{2}{*}{ Predictive variables } & \multicolumn{3}{|c|}{ Caesarean section } & \multicolumn{3}{|c|}{ Preterm birth } & \multicolumn{3}{|c|}{ Apgar $1^{\prime}<7$} \\
\hline & OR & $95 \% \mathrm{CI}$ & $p$ & OR & $95 \% \mathrm{CI}$ & $p$ & OR & $95 \% \mathrm{CI}$ & $p$ \\
\hline Glucose tolerance & & & NS & & & 0.052 & & & NS \\
\hline Negative screenees & 1 & & & 1 & & & 1 & & \\
\hline False + screenees & 1.06 & $0.91-1.23$ & NS & 1.02 & $0.77-1.34$ & NS & 0.83 & $0.60-1.14$ & NS \\
\hline ADA-only-GDM & 0.95 & $0.67-1.35$ & NS & 0.53 & $0.23-1.21$ & NS & 1.22 & $0.65-2.29$ & NS \\
\hline NDDG-GDM & 1.21 & $0.99-1.47$ & 0.054 & 1.44 & $1.04-2.00$ & 0.028 & 0.89 & $0.65-1.47$ & NS \\
\hline Maternal BMI & & & $<0.0001$ & & & NS & & & NS \\
\hline $\mathrm{Q} 1:<21.5 \mathrm{~kg} / \mathrm{m}^{2}$ & 1 & & & 1 & & & 1 & & \\
\hline Q2: $21.5-23.6 \mathrm{~kg} / \mathrm{m}^{2}$ & 1.08 & $0.91-1.28$ & NS & 0.83 & $0.62-1.12$ & NS & 1.18 & $0.85-1.64$ & NS \\
\hline Q3: $23.7-26.1 \mathrm{~kg} / \mathrm{m}^{2}$ & 1.14 & $0.97-1.35$ & NS & 1.00 & $0.75-1.33$ & NS & 1.06 & $0.76-1.48$ & NS \\
\hline Q4: $>26.1 \mathrm{~kg} / \mathrm{m}^{2}$ & 1.44 & $1.23-1.70$ & $<0.0001$ & 0.86 & $0.64-1.16$ & NS & 1.26 & $0.91-1.75$ & NS \\
\hline Fetal sex (male) & 1.06 & $0.94-1.19$ & NS & 1.10 & $0.89-1.35$ & NS & 0.86 & $0.68-1.08$ & NS \\
\hline Gestational age & 0.89 & $0.87-0.92$ & $<0.0001$ & 0.99 & $0.97-1.02$ & NS & 0.88 & $0.83-0.93$ & $<0.0001$ \\
\hline Maternal age & 1.02 & $1.01-1.03$ & 0.004 & - & - & - & 0.99 & $0.97-1.01$ & NS \\
\hline Macrosomia (yes) & 1.86 & $1.48-2.34$ & $<0.0001$ & 5.35 & $2.01-14.3$ & NS & 1.68 & $1.08-2.61$ & 0.02 \\
\hline PIH (yes) & 1.78 & $1.26-2.49$ & 0.001 & 2.83 & $1.74-4.63$ & NS & 1.26 & $0.63-2.52$ & NS \\
\hline
\end{tabular}

Maternal BMI was modelled as a categorical variable (quartiles), and maternal age as a continuous variable $A D A$-only-GDM American

Diabetes Association-only

gestational diabetes mellitus, $N D D G-G D M$ NDDG gestational diabetes mellitus, $L G A$ large for gestational age, $P I H$ pregnancy-induced hypertension, $O R$ odds ratio 
BMI. The categories of very low, low, intermediate and high risk were defined as corresponding to a sum of 2, 3-4, $5-6$ or $7-8$ in this scale respectively. In the lower quartile for age ( $<26$ years) we observed a 4.3 and $1.5 \%$ prevalence of GDM according to NDDG and ADA criteria. Except for the category with the lowest risk according to BMI and the combined score, the relative increase in GDM prevalence with ADA criteria displayed an inverse relationship with the risk category according to age (34.8-34.7-31.7-27.2\%, $p<0.001)$, BMI $(33.9-41.8-32.1-25 \%, p<0.001)$ and the combined score $(20-40-34.3-22.5 \%, p<0.001)$.

Significantly predictive models were constructed for the two primary outcome variables (macrosomia and Caesarean section). Glucose tolerance was a significant predictor in both models (Table 2). Nevertheless, ADA-only-GDM category (untreated) was not associated with a significantly different risk, whereas NDDG-GDM (treated) had an increased risk of macrosomia (OR 1.47, CI 1.06-2.06) and borderline risk of Caesarean section (OR 1.21, CI 0.991.47). Predictive models were also constructed for four secondary outcomes (PIH, preterm birth, LGA and Apgar $\left.1^{\prime}<7\right)$ with glucose tolerance being included in the four models (Table 2). Women with ADA-only-GDM had a significantly increased risk of PIH (OR 2.34, CI 1.15-4.77) and LGA newborns (OR 1.44, CI 1.02-2.03), whereas women with NDDG-GDM had a significant increase in the frequency of PIH (OR 2.03, CI 1.30-3.16) and preterm birth (OR 1.44, CI 1.04-2.00). No significant predictors were found for MCM, perinatal mortality or Apgar $5^{\prime}<7$.

\section{Discussion}

This study was designed to determine the potential impact of adopting ADA criteria for GDM diagnosis on prevalence and morbidity in the Spanish population. The $8.8 \%$ prevalence of GDM according to the NDDG criteria was in the middle range of Spanish [16-20] and worldwide rates. There are unquestionable ethnic differences in GDM prevalence, with non-Caucasian women being at higher risk [8, 21-23], but in our study the high GDM prevalence was not related to non-Caucasian ethnicity. As in previous reports $[21,24,25]$, higher maternal age and BMI were associated with GDM. The relatively older age of this cohort could partially explain the high GDM prevalence. However, ethnicity could be another factor. People from European Mediterranean countries define themselves as Caucasian, but in terms of diabetes mellitus prevalence, the risk differs between European Mediterranean and non-Mediterranean countries [26]. Furthermore, in their classic paper on GDM prevalence according to country of birth, Beischer et al. [27] reported the risk as being $37 \%$ higher in women from European Mediterranean countries than in those from Northern Europe.

The $11.6 \%$ overall prevalence of GDM using ADA criteria was higher than previously reported in a small Spanish study [16]. This prevalence implies a $31.8 \%$ relative increase in GDM diagnosis according to NDDG criteria. Although the increment in prevalence with ADA criteria $(2.8 \%)$ was higher than that found in previous studies $(0.5-1.5 \%)$, the relative increase was lower [10, 13]. Ferrara et al. [10] reported that proportional increases in prevalence were higher in subgroups at low risk according to age or ethnicity, and the present study would extend this feature to populations.

If ADA criteria were to replace NDDG criteria, the number of pregnant women diagnosed with GDM would greatly increase, thus raising the burden of prenatal care. However, the decision to use ADA thresholds should only be made to prevent maternal and perinatal complications. The Toronto Tri-Hospital Gestational Diabetes Project [4, 28] showed that women with untreated ADA-only-GDM had higher rates of Caesarean section and macrosomia than both normoglycaemic women and women with more severe NDDG-GDM who had received specific treatment. Additional studies have also justified shifting from NDDG to ADA criteria $[9,29-31]$, but this is not a unanimous conclusion [13].

According to multiple regression analysis, women with ADA-only-GDM differ from negative screenees in two secondary outcome variables (LGA and PIH) but no primary variables. Again, according to multiple regression analysis and vs negative screenees, women with NDDG-GDM had a higher risk of macrosomia, Caesarean section (borderline), PIH and prematurity, but not of LGA. Predictors of analysed outcome variables are consistent with current knowledge for macrosomia/LGA [32, 33], Caesarean section [34, 35], PIH $[4,36]$, preterm birth [37] and low Apgar score [38, 39], but we found neither increased BMI nor abnormal glucose tolerance to be predictors for MCM. With regard to Caesarean section, we should emphasise that some authors found no increased risk in ADA-only-GDM [31, 40]. The rate of PIH in the present study was similar to that found in a Spanish study published 17 years ago [13] and is within the lower range of published reports. In the negative screenees group we observed $1.7 \% \mathrm{PIH}$ including pre-eclampsia, vs $4.9 \%$ pre-eclampsia only in the corresponding group of the Toronto Tri-Hospital Study [4], or 3.7\% PIH including pre-eclampsia in the normal weight group in a study of glucose-tolerant women [41]. The rate of PIH including pre-eclampsia that we observed in the ADA-only-GDM group $(3.8 \%)$ was lower than the aforementioned rate of pre-eclampsia only in the negative screenees group of the Toronto Tri-Hospital study.

We can presume that if women with ADA-only-GDM received the same metabolic therapy as those with NDDGGDM, the risk of LGA and PIH in the former would be similar to or better than that in women with NDDG-GDM. Nevertheless, we are concerned that with tight metabolic control, the rate of SGA newborns in the ADA-only-GDM group could increase to a figure similar to or higher than that in NDDG-GDM women [42], cancelling out some of the benefits of reducing the rate of LGA newborns.

This study has two theoretical weaknesses. In contrast with Sermer et al. [4], the diagnostic strategy did not include an OGTT in every pregnant woman. We must therefore assume that we have included some women with GDM in the negative screenees group. Consequently, as we 
may have underestimated the overall prevalence of GDM, and particularly that of ADA-only-GDM, the relative increase in GDM prevalence with ADA criteria should be somewhat higher. In addition, as this study was not blinded, a higher risk of Caesarean section in women with ADAonly-GDM could have been attributed to a biased obstetric practice. However, this was not the case. The strength of the study is that it was adequately powered to detect a different outcome in the ADA-only-GDM group. The first column in Table 1 indicates that baseline assumptions were correct for macrosomia and PIH, but not for Caesarean section. Nevertheless, additional calculations indicate that the estimated sample size should also be sufficient to detect a $40 \%$ increase in the rate of Caesarean sections with the baseline rate observed in the study. The rate of Caesarean section was higher in women with NDDG GDM (a 5.6\% increase in crude rates and borderline significance in multivariate analysis). This higher rate could be accounted for by the $2.8 \%$ increase in macrosomia and the $2.5 \%$ increase in PIH in this group. Even when this study was not specifically designed to analyse the 'practice style effect' [28] towards an increased rate of Caesarean section in women with a diagnosis of GDM, these figures do not support a substantial effect.

According to our data, adoption of ADA criteria would increase the prevalence of GDM by $31.8 \%$. However, we do not consider that a change in diagnostic criteria is warranted in our setting as the contribution of these additionally diagnosed cases to adverse GDM outcomes is not substantial.

Collaborators

Additional members of the Spanish Group for the study of the impact of Carpenter and Coustan GDM thresholds were: C. Bach, Hospital Universitari de Girona Doctor Josep Trueta, Girona; M. D. Maldonado, O. Rodriguez, I. Díaz, O. Gutiérrez, A. Carazo and M. Martín, Hospital Virgen de la Salud, Toledo; M. Navarro, P. Velasco and J. Sancho-Miñano, Hospital Universitario Virgen de las Nieves, Granada; L. Blesa, M. Sánchez-Dehesa and E. Faure, Hospital Clínico Universitario Lozano Blesa, Zaragoza; M. N. Suárez, Hospital Universitario de Canarias, Tenerife; A. Santcalpe, Hospital Mutua de Terrassa; I. Rodriguez, Complejo Hospitalario Universitario Xeral-Cíes de Vigo; J. C. Martínez, S. Regel and A. Picó, Hospital General Universitario, Alicante; W. Plasencia and R. García, Hospital Universitario Materno-Infantil de Canarias, Las Palmas de Gran Canaria; T. Montoya and S. Monereo, Hospital Universitario de Getafe; P. Martín-Vaquero, L. Herranz, M. Jañez and M. J. Delgado, Hospital La Paz, Madrid; I. Mascarell, P. Cubells and R. Casañ, Hospital Universitario Dr Peset, Valencia; R. Gironés, Hospital Clínico de Valencia; and J. M. Adelantado and G. Ginovart, Hospital de Sant Pau, Barcelona.
Acknowledgements The views expressed in the article are those of the authors. We thank M. García (Hospital Universitari de Girona Doctor Josep Trueta, Girona) and I. Janin (Universidad Miguel Hernández) for statistical support. This work was sponsored by an unrestricted grant from Lilly Laboratories in Spain and supported by the Catalan Association of Diabetes, the Catalan Society of Gynaecology and Obstetrics, the Spanish Society of Diabetes and the Spanish Society of Gynaecology and Obstetrics. This work was supported by research grants from the Instituto de Salud Carlos III (RCMN C03/08, RGDM G03/212, RGTO G03/028).

\section{References}

1. Metzger BE (1991) Summary and recommendations of the third international workshop-conference on gestational diabetes mellitus. Diabetes 40[Suppl 2]:197-201

2. Langer $\mathrm{O}$, Rodriguez DA, Xenakis EM, McFarland MB, Berkus MD, Arrendondo F (1994) Intensified versus conventional management of gestational diabetes. Am J Obstet Gynecol 170:1036-1046; discussion 1046-1037

3. Kjos SL, Buchanan TA (1999) Gestational diabetes mellitus. N Engl J Med 341:1749-1756

4. Sermer M, Naylor CD, Farine D et al (1998) The Toronto trihospital gestational diabetes project. A preliminary review. Diabetes Care 21[Suppl 2]:B33-B42

5. Carpenter MW, Coustan DR (1982) Criteria for screening tests for gestational diabetes. Am J Obstet Gynecol 144:768-773

6. National Diabetes Data Group (1979) Classification and diagnosis of diabetes mellitus and other categories of glucose intolerance. Diabetes 28:1039-1057

7. American Diabetes Association (2000) Gestational diabetes mellitus. Diabetes Care 23:S77-S79

8. Dooley SL, Metzger BE, Cho NH (1991) Gestational diabetes mellitus. Influence of race on disease prevalence and perinatal outcome in a US population. Diabetes 40[Suppl 2]:25-29

9. Magee MS, Walden CE, Benedetti TJ, Knopp RH (1993) Influence of diagnostic criteria on the incidence of gestational diabetes and perinatal morbidity. JAMA 269:609-615

10. Ferrara A, Hedderson MM, Quesenberry CP, Selby JV (2002) Prevalence of gestational diabetes mellitus detected by the national diabetes data group or the Carpenter and Coustan plasma glucose thresholds. Diabetes Care 25:1625-1630

11. González NL, Medina V, Suárez MN, Clemente C, Seral E (2002) Base de datos perinatales nacionales del año 2000. Prog Obstet Gynecol 45:510-516

12. Comino-Delgado R (1986) Hypertensive states of pregnancy in Spain. Clin Exp Hyper B 5:217-230

13. Schwartz ML, Ray WN, Lubarsky SL (1999) The diagnosis and classification of gestational diabetes mellitus: is it time to change our tune? Am J Obstet Gynecol 180:1560-1571

14. Garcia-Patterson A, Martin E, Ubeda J et al (2003) Nurse-based management in patients with gestational diabetes. Diabetes Care 26:998-1001

15. Santamaria Lozano R, Verdú Martín L, Martín Caballero C, García López G (1998) Tablas españolas de pesos neonatales según edad gestacional. Ed Artes Gráficas Beatulo, Badalona

16. Gorgojo Martinez JJ, Almodovar Ruiz F, Lopez Hernandez E, Donnay Candil S (2002) Incidence of gestational diabetes mellitus according to different diagnostic criteria in the southeast Madrid area. Influence of diagnosis on materno-fetal parameters. Rev Clin Esp 202:136-141

17. Diez JJ, Grande C, Pallardo LF, de la Morena ML, Ibars MT (1989) Detection of gestational diabetes with the 50-gram glucose test: prevalence and relationship with to factors. Med Clin (Barc) 93:41-45 
18. Corcoy R, Cerqueira MJ, Codina M, Ordoñez J, de Leiva A, Cabero L (1988) Diagnóstico de la diabetes gestacional: importancia del screening matutino y utilidad relacionada con los factores de riesgo. Avances Diabetologia 1:90-94

19. Ricart W, Bach C, Fernandez-Real JM, Biarnes J, Sabria J (1999) Impacto del screening selectivo para diabetes gestacional en una población española. Med Clin (Barc) 113:331-333

20. Jimenez-Moleon JJ, Bueno-Cavanillas A, Luna-Del-Castillo JD, Garcia-Martin M, Lardelli-Claret P, Galvez-Vargas R (2002) Prevalence of gestational diabetes mellitus: variations related to screening strategy used. Eur J Endocrinol 146:831-837

21. Weijers RNM, Bekedam DJ, Smulders YM (2002) Determinants of mild gestational hyperglycemia and gestational diabetes mellitus in a large Dutch multiethnic cohort. Diabetes Care 25:72-77

22. Koukkou E, Taub N, Jackson P, Metcalfe G, Cameron M, Lowy C (1995) Difference in prevalence of gestational diabetes and perinatal outcome in an innercity multiethnic London population. Eur J Obstet Gynecol Reprod Biol 59:153-157

23. Dornhorst A, Paterson CM, Nicholls JS et al (1992) High prevalence of gestational diabetes in women from ethnic minority groups. Diabet Med 9:820-825

24. Sebire NJ, Jolly M, Harris JP et al (2001) Maternal obesity and pregnancy outcome: a study of 287,213 pregnancies in London. Int J Obes Relat Metab Disord 25:1175-1182

25. Aberg A, Rydhstroem H, Frid A (2001) Impaired glucose tolerance associated with adverse pregnancy outcome: a population-based study in southern Sweden. Am J Obstet Gynecol $184: 77-83$

26. e-Atlas. IDF (2003) http://www.idf.org/e-atlas/home, accessed in December 2003

27. Beischer NA, Wein P, Sheddy MT, Steffen B (1996) Identification and treatment of women with hyperglycemia diagnosed during pregnancy can significantly reduce perinatal mortality rates. Aust N Z J Obstet Gynecol 36:239-247

28. Naylor CD, Sermer M, Chen E, Sykora K (1996) Cesarean delivery in relation to birth weight and gestational glucose tolerance: pathophysiology or practice style? Toronto trihospital gestational diabetes investigators. JAMA 275:1165-1170

29. Deerochanawong C, Putiyanum C, Wongsuryrat M, Serirat S, Jinayon P (1996) Comparison of national diabetes data group and word health organization criteria for detecting gestational diabetes mellitus. Diabetologia 39:1070-1073
30. Pettitt DJ, Bennett PH, Hanson RL, Narayan KM, Knowler WC (1994) Comparison of World Health Organization and National Diabetes Data Group procedures to detect abnormalities of glucose tolerance during pregnancy. Diabetes Care 17:1264-1268

31. Rust OA, Bofill JA, Andrew ME et al (1996) Lowering the threshold for the diagnosis of gestational diabetes. Am J Obstet Gynecol 175:961-965

32. Okun N, Verma A, Mitchell BF, Flowerdew G (1997) Relative importance of maternal constitutional factors and glucose intolerance of pregnancy in the development of newborn macrosomia. J Matern Fetal Med 6:157-162

33. Xiao R, Sorensen TK, Williams MA, Luthy DA (2003) Influence of pre-eclampsia on fetal growth. J Matern Fetal Neonatal Med 13:157-162

34. Sims CJ, Meyn L, Caruana R, Rao RB, Mitchell T, Krohn M (2000) Predicting cesarean delivery with decision tree models. Am J Obstet Gynecol 183:1198-1206

35. Michlin R, Oettinger M, Odeh M et al (2000) Maternal obesity and pregnancy outcome. Isr Med Assoc J 2:10-13

36. Parazzini F, Bortolus R, Chatenoud L et al (1996) Risk factors for pregnancy-induced hypertension in women at high risk for the condition. Italian study of aspirin in pregnancy group. Epidemiology 7:306-308

37. Hedderson MM, Ferrara A, Sacks DA (2003) Gestational diabetes mellitus and lesser degrees of pregnancy hyperglycemia: association with increased risk of spontaneous preterm birth. Obstet Gynecol 102:850-856

38. Spellacy WN, Miller S, Winegar A, Peterson PQ (1985) Macrosomia-maternal characteristics and infant complications. Am J Obstet Gynecol 66:158-161

39. Catlin EA, Carpenter MW, Brann BS et al (1986) The apgar score revisited: influence of gestational age. J Pediatr 109:865868

40. Pennison EH, Egerman RS (2001) Perinatal outcomes in gestational diabetes: a comparison of criteria for diagnosis. Am J Obstet Gynecol 184:1118-1121

41. Jensen DM, Damm P, Soensen B et al (2003) Pregnancy outcome and prepregnancy body mass index in 2,459 glucosetolerant Danish women. Am J Obstet Gynecol 189:239-244

42. Langer O, Levy J, Brustman L, Anyaegbunam A, Merkatz R, Divon M (1989) Glycemic control in gestational diabetes mellitus - how tight is tight enough: small for gestational age versus large for gestational age? Am J Obstet Gynecol 161: 646-653 